\title{
Morphological Effect of Diode Laser Irradiation of Periapical Lesion in Rat
}

\author{
Sultan Zeb Khan, Eitoyo Kokubu, Morito Tsuruoka, Satoshi Murakami, Kenichi Matsuzaka, Takashi Inoue
}

\begin{abstract}
The aim of this study was to evaluate the morphological effects of diode laser irradiation in the experimentally produced periapical lesion in rat. Fourteen adult male Sprague-Dawley rats weighing approximately $200 \mathrm{gm}$ each were used. Pulp was extirpated from the mesial root of the maxillary first molar using 06 to $25 \mathrm{~mm}$ conventional reamers and files. After extirpation, the root canal was exposed to oral flora for 4 weeks to allow periapical periodontitis to develop. After the development of periapical periodontitis, the lesions were irradiated using a diode laser at $5 \mathrm{~W}$ for 5 seconds. The root canal was then sealed with cavity filling material for another 4-week period. After 4 weeks, the experimental rats were sacrificed by cervical dislocation. The maxillary first molar was then collected along with the surrounding tissue, which was processed in the laboratory. Hematoxylin and eosin and immunohistochemical staining were used to observe the morphological effects. Proliferating cell nuclear antigen (PCNA), STRO-1 and CD44 were used as the primary antibodies for the immunohistochemical study.

A reduction in inflammatory cells, which were mainly composed of lymphocytes, was observed in the periapical lesions after irradiation. The number of PCNA-positive cells increased to approximately twice that observed in the nonirradiated control group. These PCNA-positive cells included STRO-1 and CD44-positive cells, indicating enhancement of wound healing and reduction in inflammatory cells.

The present results showed that diode laser irradiation enhanced proliferation of PCNA-positive cells, which included STRO-1 and CD44-positive cells. This increase in these types of cell may improve wound healing in periapical lesions.
\end{abstract}

Keywords: Periapical periodontitis, Diode laser, PCNA, Laser irradiation, STRO-1.

How to cite this article: Khan SZ, Kokubu E, Tsuruoka M, Murakami S, Matsuzaka K, Inoue T. Morphological Effect of Diode Laser Irradiation of Periapical Lesion in Rat. Int J Laser Dent 2013;3(2):37-43.

Source of support: Nil

Conflict of interest: None declared

\section{INTRODUCTION}

Low-level laser therapy (LLLT) is an important tool in the dental-medical field., ${ }^{1,2}$ Due to its impact on cell growth, LLLT has been suggested to favor tissue repair and influence attachment and proliferation of gingival fibroblasts in vitro. ${ }^{3}$ Meanwhile, another study has shown that LLLT affects bone cells, significantly promoting proliferation and differentiation of human osteoblasts in vitro in comparison with nonirradiated cells. ${ }^{4}$ One potential use of lasers in dentistry, and particularly in endodontic therapy, is as an aid in the cleaning and sealing of root canals prior to obturation. ${ }^{5}$ Two types of laser are used: helium neon lasers with a wavelength of $633 \mathrm{~nm}$, and semiconductor lasers emitting light in the range of 780 to $950 \mathrm{~nm}$. It has been suggested that low-energy laser light reduces pain, accelerates wound healing, and exerts a positive effect on inflammatory processes. ${ }^{6}$ Some studies have shown that LLLT accelerates wound healing ${ }^{7}$ and reduces pain, ${ }^{8,9}$ possibly by stimulating oxidative phosphorylation ${ }^{10,11}$ and reducing inflammatory responses. The basic principle underlying the biomodulation of cells by laser therapy is that irradiation at a specific wavelength alters cellular behavior by acting on the mitochondrial respiratory chain ${ }^{12}$ or membrane calcium channels, ${ }^{13}$ promoting an increase in cell metabolism and proliferation. ${ }^{14}$

Infection is a major cause of pulpal and periradicular diseases. ${ }^{15}$ Bacteria and their byproducts are considered to be the primary etiologic agents of pulpal necrosis and periapical lesions. Therefore, the elimination of bacteria and their byproducts is one of the most important steps in endodontic treatment. ${ }^{16,17}$ Representative inflammatory periradicular pathologies are universal and mainly involve the apical periodontium, with no predominance of race, sex or age. ${ }^{18}$ Inflammation of tooth-supporting structures accompanied by an impaired repair process usually leads to severe tissue damage, such as bone loss and subsequent tooth loss. ${ }^{19}$ An anti-inflammatory effect and the stimulation of the wound healing process have been reported as biological effects of LLLT. ${ }^{15}$ Kana et al. reported the enhancement of wound healing by laser irradiation using an in vivo experimental system. ${ }^{20}$ Mesteret et al. were the first to use laser irradiation as a phototherapeutic means of stimulating and/or accelerating wound healing in the 1970s. ${ }^{21,22}$ Despite extensive research, however, some controversy still remains as to the precise effect of such therapy on wound healing. ${ }^{23,24}$ Although conventional treatment cannot be performed with laser irradiation alone, it is still considered a useful adjunct. ${ }^{25}$ The purpose of this study was to evaluate the morphological effects of diode laser irradiations in the experimentally produced periapical lesion of rat, and enhancing healing around the tooth apex when used in combination with conventional root canal treatment. 


\section{MATERIALS AND METHODS}

All animal studies were carried out in compliance with the Guidelines for the Treatment of Experimental Animals at Tokyo Dental College $(2,23,206)$. Sprague-Dawley male rats $(\mathrm{n}=50)$, each weighing $200 \mathrm{gm}$, were used for this in vivo study. All animals were sacrificed by cervical dislocation. The upper first molars and whole maxilla were then harvested and fixed in formalin. Two groups of the animals were made one experimental group, in which initially periapical lesions were developed and these periapical lesions were irradiated with diode laser, and another control group, without any experimental activity.

\section{DEVELOPMENT OF PERIAPICAL LESION}

Animals were anesthetized with an intraperitoneal injection of sodium thiopental (Ravonal; Tanabe, Osaka, Japan; 0.3 $\mathrm{ml} / 100$ gm body weight). A stainless steel tungsten carbide bur (06) was used to prepare an access cavity in the upper first molar mesial root. The pulp was then extirpated using 06 to $25 \mathrm{~mm}$ conventional reamers and files, as shown in Figs $1 \mathrm{~A}$ and $\mathrm{B}$. The root canal was then exposed to oral flora for 4 weeks to allow periapical periodontitis to develop.

\section{Irradiation of Periapical Lesion}

After 4 weeks, the rats were anesthetized with an intraperitoneal injection of sodium thiopental. The exposed root canals were washed with normal saline and then disinfected with hydrogen peroxide three times. Next, the root canals were fully dried prior to irradiation with an SP diode solid-state P laser (Diode laser of Panasonic Co., Osaka, Japan), employing a repeated pulse, density of $10 \%$ duty and emitting at $805 \mathrm{~nm}$. The periapical lesions were irradiated at $5 \mathrm{~W}$ for 5 seconds. The root canal was then filled and sealed with cavity filling material and left for another 4 weeks.

The delivery system of the Diode P-Laser consisted of a fiber-optic tube terminating in a hand piece with tip $400 \mu \mathrm{m}$ in diameter and $8 \mathrm{~mm}$ in length. The tip of the laser was not in direct contact with the periapical lesion during exposure. In all, a total energy of $2.5 \mathrm{~J}$ was employed.

\section{Histological and Immunohistochemical Study}

Animals were sacrificed by cervical dislocation at 4 weeks after irradiation. The roots together with the surrounding alveolar bone and muscle tissue were excised and fixed in $10 \%$ neutral buffered formalin solution for 5 days. The maxillary molars and surrounding tissue were then decalcified in 10\% EDTA solution for 4 weeks. All samples were then washed in running tap water, dehydrated in a series of alcohol and embedded in paraffin. Next, the samples were cut into $4 \mu \mathrm{m}$ thick sections and stained with hematoxylin and eosin (H\&E). Serial sections were used for immunostaining. The sections were treated with $30 \%$ hydrogen peroxide and methanol solution for 15 minutes at room temperature to inactivate endogenous peroxidase activity. Tissue samples were blocked with $1 \%$ bovine serum albumin (BSA; Roche Applied Sciences, IN, USA) in phosphate-buffered saline (PBS; Invitrogen, Gibco, CA, USA) for 30 minutes at room temperature. Samples were incubated with proliferating cell nuclear antigen (PCNA), STRO-1 and CD44 as primary antibodies (dilution of each antibody, 1:200) in PBS containing 1\% BSA for 1 hour at room temperature. Specimens were then washed and incubated with a biotinylated secondary antibody: NichireiHistofine simple-stain MAX-PO (Nichirei, Tokyo, Japan) for 45 minutes at room temperature. After washing with PBS three times for 3 minutes each time, the samples were stained with Nichirei-Histofine simple stain DAB (Nichirei) and counterstained with hematoxylin. Paraffin sections were observed using UPM Axiophoto (Carl Zeiss).

\section{Morphometric Analysis}

The periapical area of the maxillary first molar mesial root in both the control and experimental groups was divided into three areas: one immediately below the apex, and one on the right and one on the left of the root apex, as shown in Figure 1E.

\section{Ratio of PCNA-Positive Cells}

Quantitative assessment was performed according to Matsuzaka et al. ${ }^{26}$ by counting PCNA-positive cells around the apex of the mesial root in both the control and experimental groups.

PCNA score $=$ number of positive cells per $100 \mu \mathrm{m}^{2}$.

Results were expressed as the percentage of PCNApositive cells \pm SD.

\section{RESULTS}

\section{Histological Study of Control and Experimental Groups in vivo}

\section{Control Group}

Rat maxillary first molar mesial root apices with no signs of pathological development were assigned to the control group, as shown in Figure 1A.

\section{Experimental Group}

The initial experimental group comprised samples with periapical periodontitis, as shown in the schema and in vivo (Figs 1C and D and 2). 


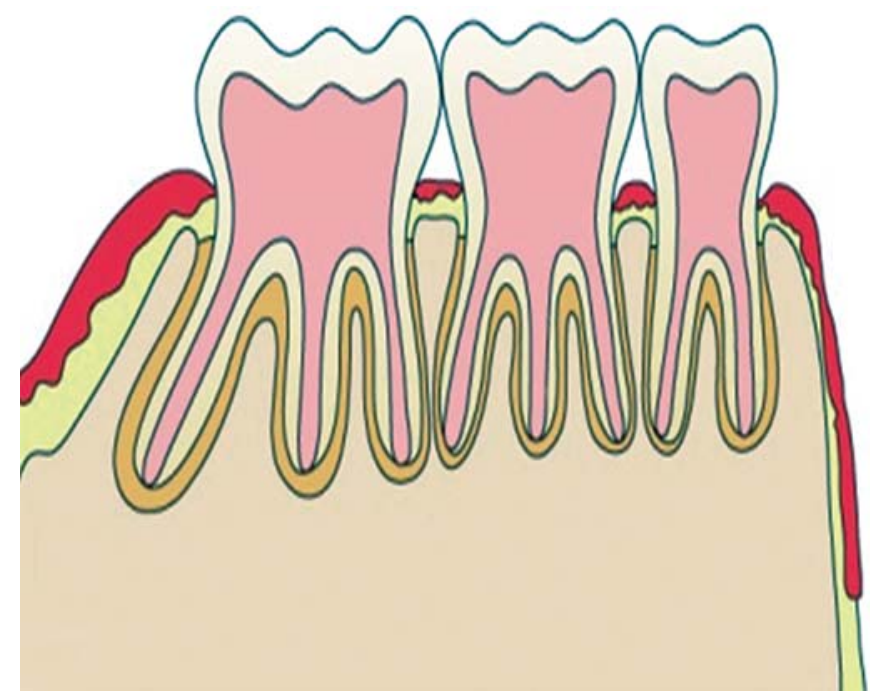

Fig. 1A: Schema of rat maxillary molars

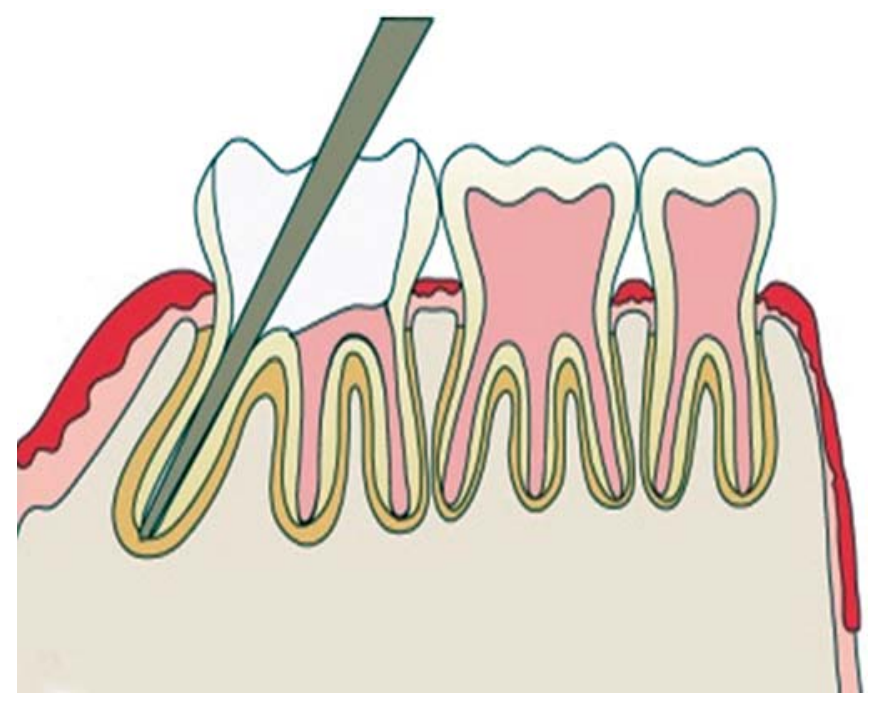

Fig. 1B: Schema of root canal preparation in maxillary first molar mesial root using conventional endodontic reamer

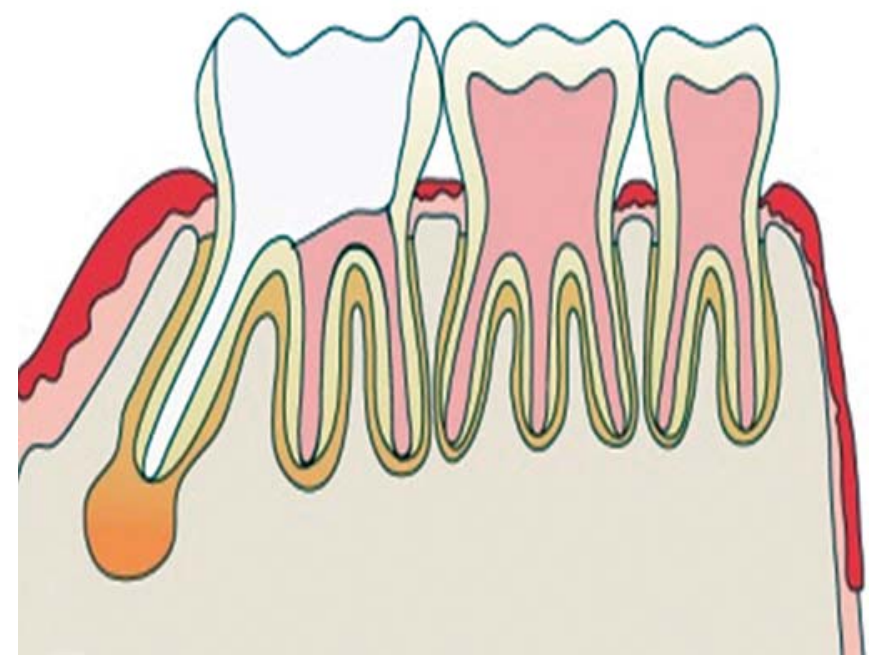

Fig. 1C: Schema of periapical lesion development in maxillary first molar mesial root

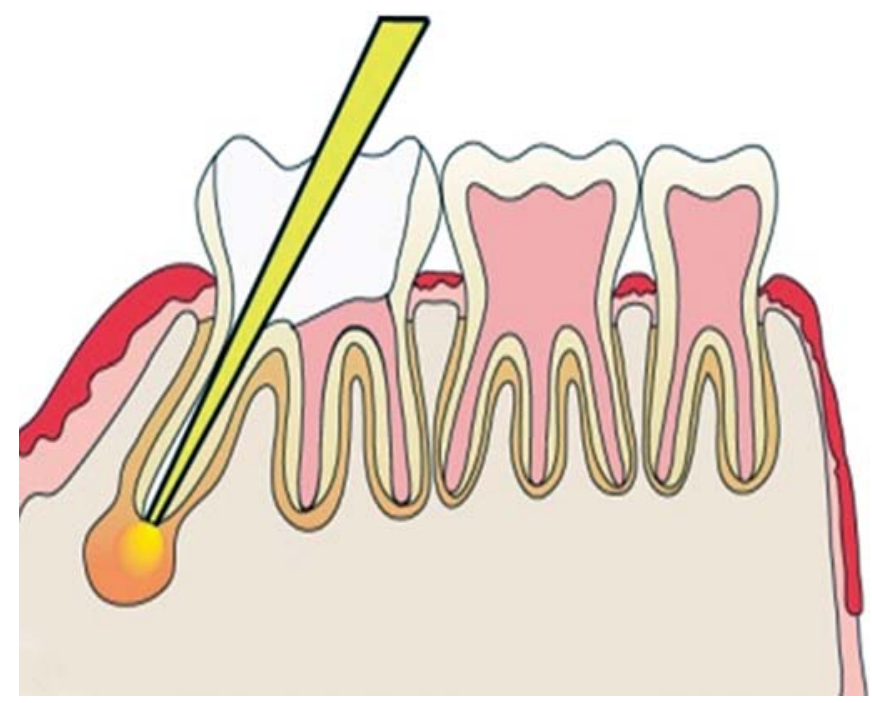

Fig. 1D: Schema of laser irradiation of periapical lesion in maxillary first molar mesial root after periapical lesion development

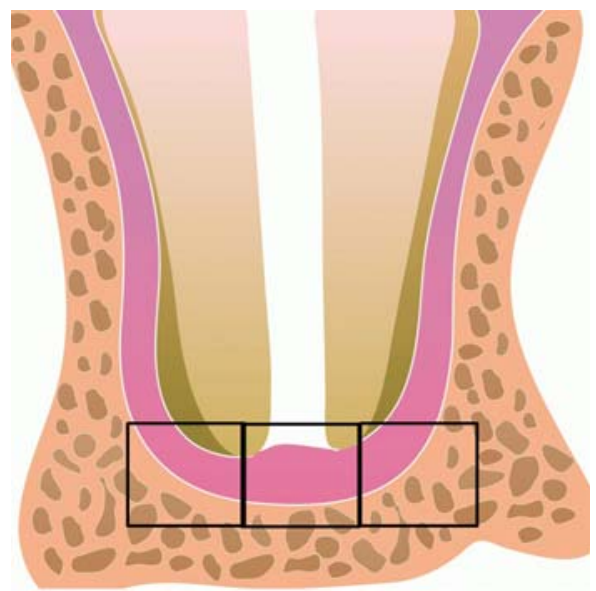

Fig. 1E: Schema showing division of periapical area of maxillary first molar mesial root into three areas (one immediately below apex, and right and left areas of root apex) for counting of PCNA-positive cells

The presence of chronic inflammatory cells, mainly lymphocytes, and alveolar bone resorption around the apex of the mesial root was taken to indicate periapical periodontitis (Fig. 2).

\section{In vivo Study of Periapical Area after Irradiation Experimental Group}

Irradiated periapical lesion: A reduction in the number of inflammatory cells, which were mainly composed of lymphocytes, was observed after irradiation. Cellular regeneration was also observed (data not shown).

\section{Immunohistochemistry}

\section{Ratio of PCNA-Positive Cells}

Control group: PCNA was used for visualization of proliferating cells in both groups as it labels all phases of 


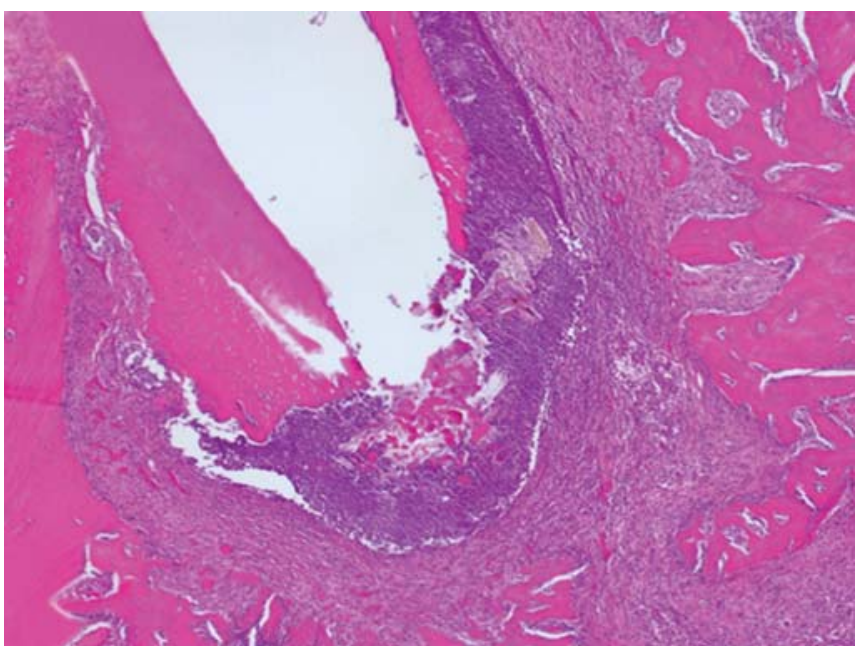

Fig. 2: H\&E staining of periapical periodontitis after 4 weeks in mesial root of maxillary first molar

the cell cycle. Fewer PCNA-positive cells were observed around the apex of the mesial root in the control group than in the experimental group, as shown in Figures 3A and 4.

Experimental group: Wound healing and cell proliferation following laser irradiation were examined by H\&E staining and immunostaining for PCNA, respectively. Wound healing was also quantitatively evaluated by calculating the percentage of PCNA-positive proliferating cells at 4 weeks after laser irradiation in the periapical area of the mesial root (Fig. 3B). The number of PCNA-positive cells in the experimental group was double that in the control group, as shown in Figure 4.

Control group STRO-1-positive cells: Positive staining for STRO-1 antibody was observed in the periodontal ligament around the apices of mesial roots with no sign of pathological development. In periodontal ligament, STRO-1-positive cells were mostly found randomly distributed in the periapical area. The majorities of STRO-1-positive cells were round and had intensely stained nuclei and little cytoplasm. Fewer STRO-1-positive cells were observed in the control group than in the experimental group, as shown in Figure 5A.

Experimental group STRO-1-positive cells: In the experimental group, cells staining positive for STRO- 1 were detected in the periodontal ligament around the middle and apical portions of the mesial root. More areas of cells showing positive staining were observed in the experimental group than in the control group. Positive staining was mainly detected in cells around the periapical area of the periodontal ligament. The STRO-1-positive cells were characterized by two different morphologies. One group had an elongated cytoplasm and nucleus, or ovoid nucleus resembling that of an endothelial cell. This type of cell was observed more frequently in the experimental than the control group. The

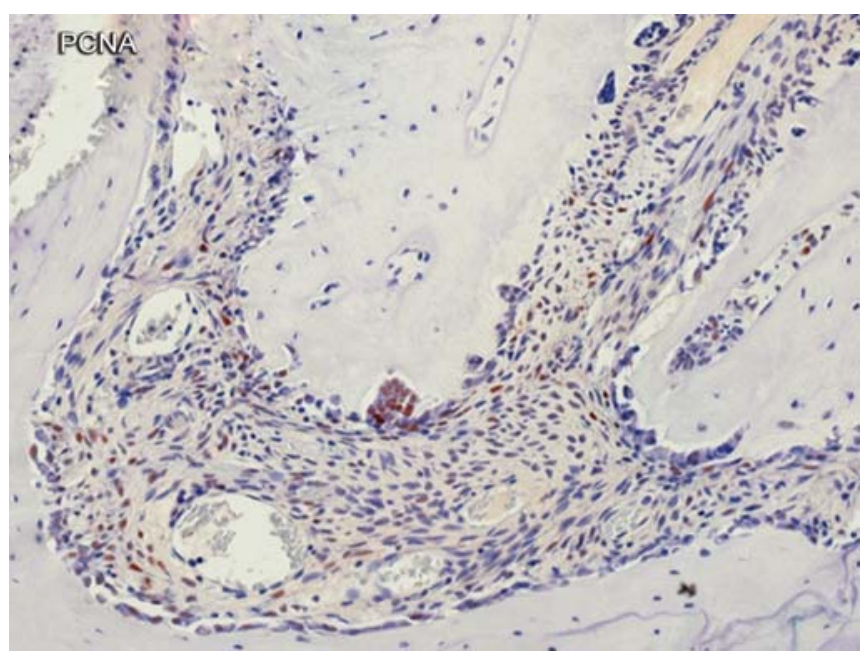

Fig. 3A: Apical area of normal mesial root immunohistochemically stained for PCNA. Positive brown staining for PCNA-positive cells observed around apex in control with no pathological development

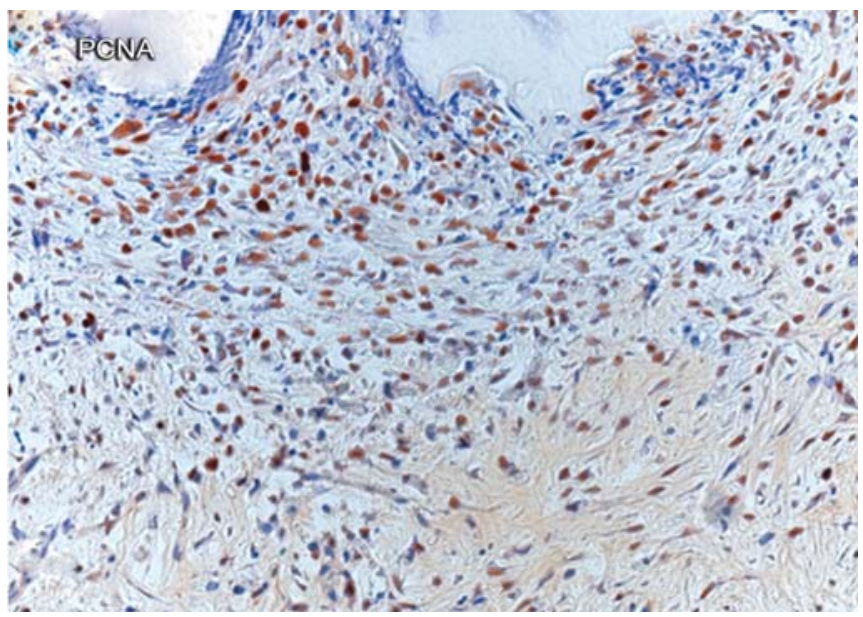

Fig. 3B: Brown staining for PCNA-positive cells in periodontal ligament at 4 weeks after obturation with gutta-percha points and diode laser irradiation. Note markedly higher rate of PCNA-positive cells indicating higher proliferative activity in laser-irradiated periapical lesion

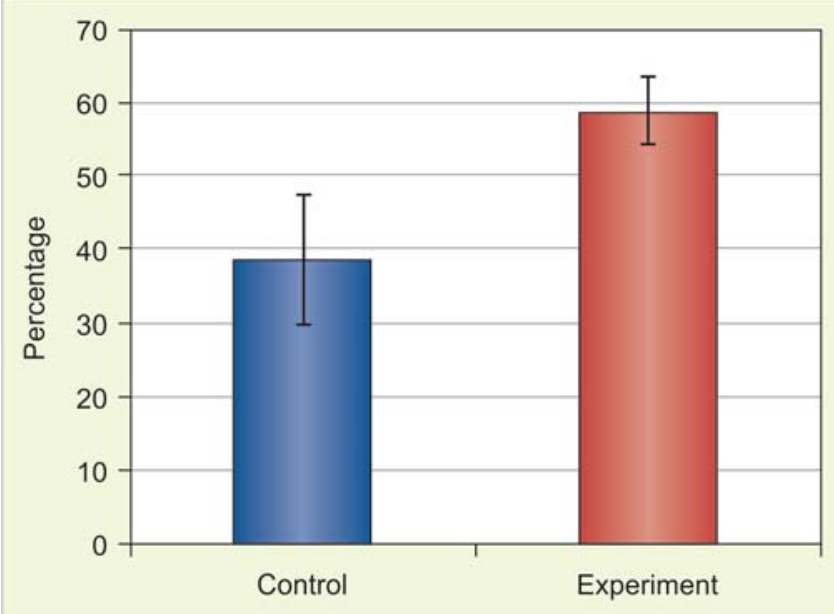

Fig. 4: Percentage of PCNA scores around apex of mesial root of first maxillary molar: PCNA score was highest (58.90\%) immediately below apex in experimental group (shown by red bar in graph). PCNA scores in control group (38.65\%) were lower than in experimental group (shown by black bar in graph) 


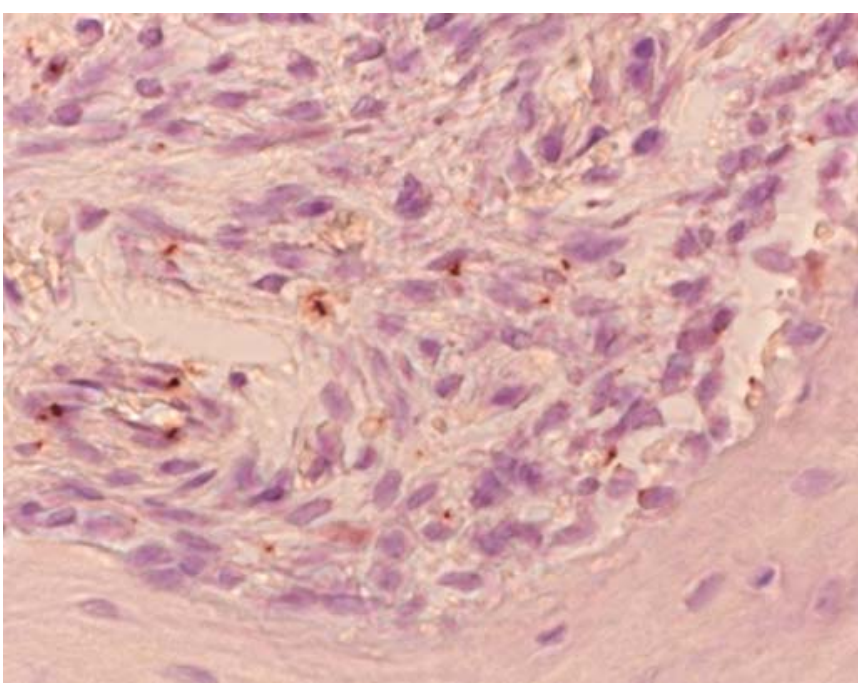

Fig. 5A: STRO-1 surface antigen in periodontal ligament in control group (without periapical periodontitis). Staining occurred in periapical area near apex of root in healthy periodontal ligament. Cells staining positive for STRO-1 antigen in healthy periodontal ligament had round nuclei and small amount of cytoplasm. A few PDL cells were positive for STRO-1 and showed intensely stained nucleus with brown stained cytoplasm

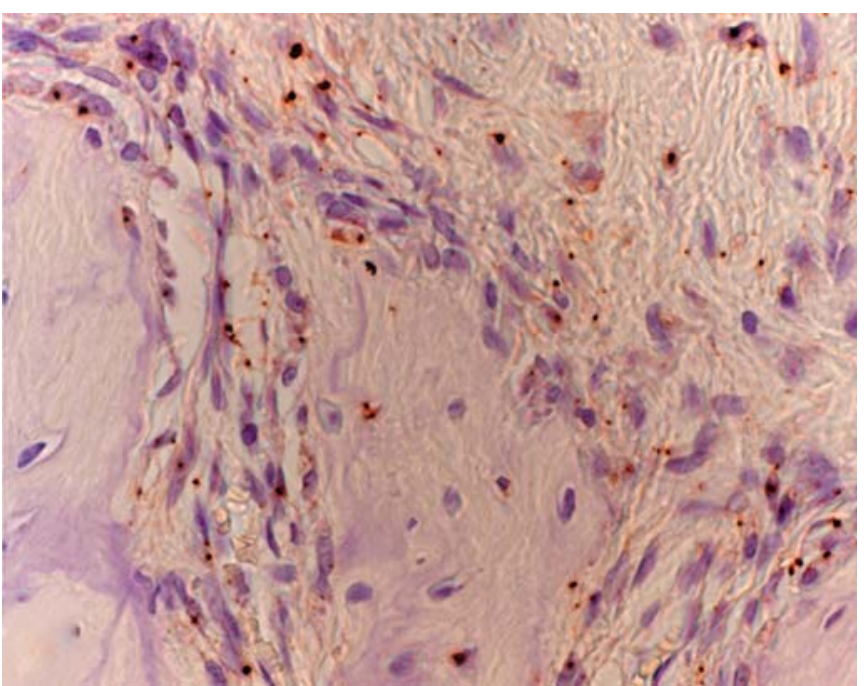

Fig. 5B: STRO-1 surface antigen in apical periodontal ligament in periapical periodontitis irradiated experimental group. STRO-1 surface antigen was sparsely distributed in periodontal ligament in laser irradiated group compared with in control. Positively stained PDL cells with STRO-1 antibody in experimental model after obturation, and laser irradiation showed two types of morphology: elongated nucleus and cytoplasm, resembling endothelial cells or round nucleus with small amount of cytoplasm

other group had large round, or oval-shaped nuclei with more intense hematoxylin staining and a smaller amount of cytoplasm; this type of cell was observed less frequently in the experimental than the control group, as shown in Figure 5B.

Control group CD44-positive cells: Paraffin sections stained for CD44 in both groups displayed a greater degree of staining than those stained for STRO-1 due to differences in the relative specificity of each marker for progenitor cells.

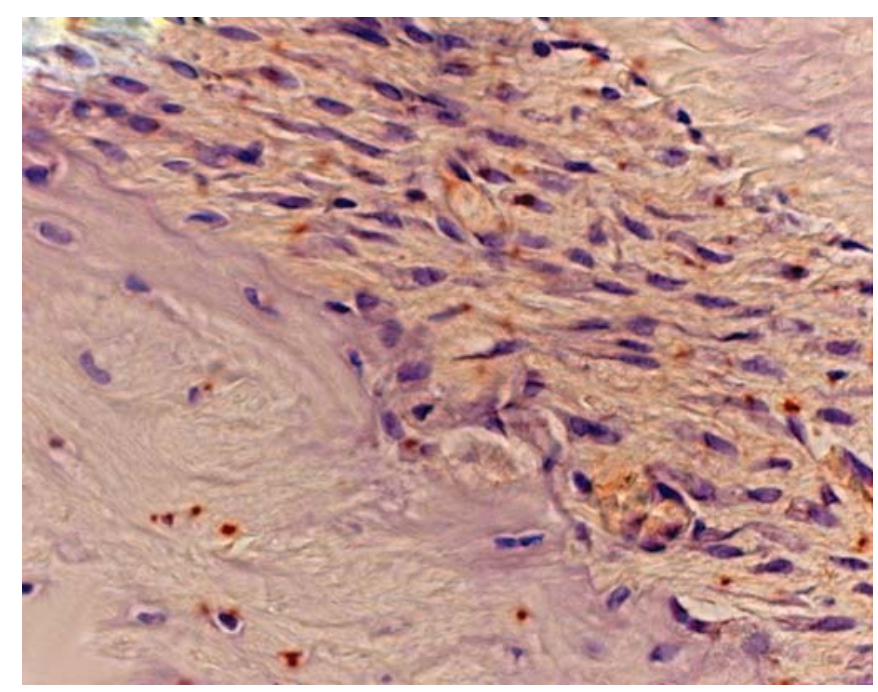

Fig. 6A: CD44 antigen in periodontal ligament in healthy normal mesial root apical area. Intense CD44 staining was observed in perivascular and extravascular areas. Two types of morphology observed were similar to those seen in STRO-1-positive control group

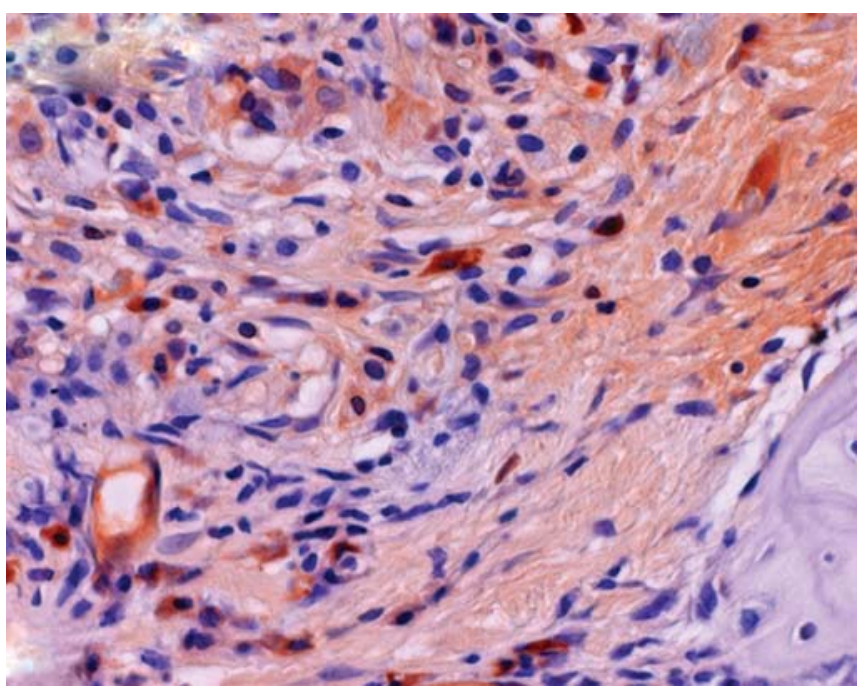

Fig. 6B: Positively stained CD44 cells in PDL in laser irradiated experimental group. Figure also shows nonspecific background staining with the two types of morphology described above. Positively stained CD44 cells were distributed randomly in apical PDL

The distribution of staining for CD44 was less specific, and general background staining was found in the periodontal ligament matrix of most sections. However, nonspecific background staining was more intense in the experimental than the control group. Positive staining was mainly detected in cells in the perivascular area of the periodontal ligament, but some stained cells were also detected in the extravascular spaces and along the cementum. Cells in the perivascular and extravascular areas showed two different morphologies: an elongated cytoplasm and nucleus resembling those of endothelial cells; or a large round, or oval-shaped nucleus 
with more intense hematoxylin staining and a smaller amount of cytoplasm. The cells in the extravascular areas and near the cementum belonged to the second group (Fig. 6A)

Experimental group CD44-positive cells: In the experimental group, cells positive for the CD44 antigen were found in the apical area and near the alveolar bone in the periodontal ligament. The pattern of distribution of CD44postive cells was similar to that in the control group. However, nonspecific background staining was more intense in the experimental group (Fig. 6B). Nonspecific background staining in the extravascular and perivascular areas was observed in the experimental group, similar to that in the control group. Cells in the extravascular area had an elongated cytoplasm and nucleus resembling those of endothelial cells (Fig. 6B).

\section{DISCUSSION}

The experimental induction of chronic periapical periodontitis in teeth in animals is important in the evaluation of new root canal materials and procedures for clinical use under similar conditions in human. ${ }^{27}$ Periapical pathoses of pulpal origin develop in response to microbial irritants in the root canal system. Persistent injury to the dental pulp usually causes irreversible pulpitis and pulpal necrosis. Irritants may be mechanical or chemical, but are most often bacterial. ${ }^{28}$ The development of periapical lesions in rat is well described in the literature, as these animals are often used in the study of pulpal and periapical alterations. Therefore, rats were used in the present study as they are easy to use and only a short time is required for the development of periapical lesions. ${ }^{29}$ The lesions became radiographically apparent after 14 days, achieving the maximum size after 28 days of pulpal exposure to the oral microflora. These results are in agreement with those of earlier studies. ${ }^{30,31}$

PCNA is a known marker of cell proliferation. ${ }^{32}$ The synthesis of PCNA begins to increase in the late $G_{1}$ phase of the cell cycle, and although it is more often expressed in actively dividing cells in the coenzyme protein of DNA polymerase $\lambda$, it is also present to some extent in restingphase cells. ${ }^{33}$

Anti-PCNA antibody has been used to identify proliferating cells in paraffin-embedded tissue sections. ${ }^{34}$ Therefore, we chose this antibody for a comparison of PCNA expression with that of other markers. In this study, PCNA antibody was used to identify proliferating cells in the PDL area after laser irradiation in conjunction with conventional root canal treatment.
According to Gronthos et al. periodontal mesenchymal stem cells are responsible for wound healing in periodontitis. Moreover, mesenchymal stem cells isolated from human periodontal ligament have been termed periodontal ligament stem cells. ${ }^{35}$ In the present study, periodontal mesenchymal stem cells were found around the periapical lesion. In accordance with the results of an earlier study by $\mathrm{NH}$ Lin et $\mathrm{al}^{36}$ these mesenchymal cells, which showed positive staining for STRO-1, anti-CD-146, and anti-CD44 antibodies in regenerating periodontal tissue, demonstrated two morphologies: they were either elongated with an ovalshaped nucleus and extended cytoplasm, or they were round and had an intensely stained nucleus and small cytoplasm. As observed in this study, mesenchymal cells always migrate from remaining periodontal ligament cells and alveolar bone, and stem cells of the periodontal ligament are involved in wound healing of the periodontal cavity. ${ }^{37}$

\section{CONCLUSION}

These results showed that diode laser irradiation induced proliferation of PCNA-positive cells, which included STRO-1, and CD44-positive cells. This suggests that LLLD enhances wound healing in periapical lesions, indicating the potential of this treatment modality as an adjunctive tool in conventional endodontic treatment.

\section{REFERENCES}

1. Posten W, Wrone DA, Dover JS, Amdt KA, Silapunt S, Alam M. Low-level laser therapy for wound healing: mechanism and efficacy. Dermatol Surg 2005 Mar;31(3):334-340.

2. Pinheiro AL. Advances and perspectives on tissue repair and healing. Photomed Laser Surg 2009 Dec;27(6):833-836.

3. Khadra M, Lyngstadaas SP, Haanaes HR, Mustafa K. Determining optimal dose of laser therapy for attachment and proliferation of human oral fibroblasts cultured on titanium implant material. J Biomed Mater Res A 2005 Apr;73(1): 55-62.

4. Stein A, Benayahu D, Maltz L, Oron U. Low-level laser irradiation promotes proliferation and differentiation of human osteoblasts in vitro. Photomed Laser Surg 2005 Apr;23(2):161166.

5. Dederich DN, Pickard MA, Vaughn AS, Tulip J, Zakariasen KL. Comparative bactericidal exposures for selected oral bacteria using carbon dioxide laser radiation. Lasers Surg Med 1990;10(6):591-594.

6. Kreisler M, Christoffers AB, Willershausen B, d'Hoedt B. Effect of low-level GaAIAs laser irradiation on the proliferation rate of human periodontal ligament fibroblasts: an in vitro study. $\mathrm{J}$ Clin Periodontol 2003 Apr;30(4):353-358.

7. Bisht D, Gupta SC, Mishra V, Mital VP, Sharma P. Effects of low intensity laser radiation on healing of open skin wounds in rats. Indian J Med Res 1994 Jul;100:43-46.

8. Harazaki M, Takemashi H, Ito A, Isshiki Y. Soft laser irradiation induced pain reduction in orthodontic treatment. Bull Tokyo Dent Coll 1998 May;39(2):95-101. 
9. Pinheiro AL, Cavacanti ET, Pinheiro TI, Alves MJ, Miranda ER, De Quevedo AS, Manzi CT, Vieira AL. Low-level laser therapy is an important tool to treat disorders of the maxillofacial region. J Clin Laser Med Surg 1998 Aug;16(4):223-226.

10. Karu T. Photobiological fundamentals of low-power laser therapy. J Quant Electr 1987;23(10):1704-1717.

11. Passarella S, Casamassima E, Molinari S, Pastore D, Quagliariello E, Catalano IM, Cingolani A. Increase of proton electrochemical potential and ATP synthesis in rat liver mitochondria irradiated in vitro by helium-neon laser. FEBS Lett 1984 Sep;175(1):95-99.

12. Karu T. Photobiology of low power laser effects. Health Phys 1989 May;56(5):691-704.

13. Smith KC. The photobiological basis of low-level laser radiation therapy. Laser Ther 1991; 3:19-24.

14. Harris DM. Biomolecular mechanisms of laser biostimulation. J Clin Laser Med Surg 1991 Aug; 9(4):277-279.

15. Kakehashi S, Staneley HR, Fitzgerald RJ. The effects of surgical exposures of dental pulps in germ-free and conventional laboratory rats. Oral Surg Oral Med Oral Pathol 1965 Sep; 20:340-349.

16. Bergenholtz G. Micro-organisms from necrotic pulp of traumatized teeth. Odontol Revy 1974;25(4):347-358.

17. Sundqvist G. Bacteriological studies of necrotic dental pulps (dissertation). Umea, Sweden: Umea University 1976; 1-93 p.

18. Neville BW, Damm DD, Allen M, Bouquot JE, editors. Patologia oral e maxillofacial. Rio de Janeiro: Ed. Guanabara Koogan; 1998; 35 p.

19. Carranza FA. Clinical diagnosis. In: Newman MG, Takei HH, Carranza FA, editors. Carranza's clinical periodontology. 9th ed. Philadelphia: WB Saunders Company 2002:p. 445.

20. Kana JS, Hutschenreiter G, Haina D, Waidekich W. Effect of low-power density irradiation on healing of open skin wounds in rats. Arch Surg 1981 Mar;116(3):294-296.

21. Schindl A, Schindl M, Pernerstorfer-Schon H, Schindl L. Lowintensity laser therapy: a review. J Invest Med 2000 Sep;48(5):312-326.

22. Mester D, Spiry T, Szende B, Tota JG. Effect of laser rays on wound healing. Am J Surg 1971 Oct;122(4):532-535.

23. Karu TI. Biomedical photonics handbook. CRC Press LLC; 2003. Chapter 48: Low-power laser therapy; p. 1-26.

24. Karu T. Low-power laser therapy. Biomedical Photonics Handbook 2003; 48:1-4.

25. Kimura Y, Wilder-Smith P, Matsumoto K. Lasers in endodontics: review. Int Endod J 2000 May;33(3):173-185.

26. Matsuzaka K, Shimono M, Inoue T. Characteristics of newly formed bone during guided bone regeneration: observations by immunohistochemistry and confocal laser scanning microscopy. Bull Tokyo Dent Coll 2001 Nov;42(4):225-234.

27. Tanomaru JM, Leonardo MR, Silva LA, Poliseli-Neto A, Tanomaru-Filho M. Histopathological evaluation of different methods of experimental induction of periapical periodontitis. Braz Dent J 2008;19(3):238-244.

28. Pezelj-Ribarić S, Magasić K, Prpić J, Miletić I, Karlović Z. Tumor necrosis factor-alpha in periapical tissue exudates of teeth with apical periodontitis. Mediators Inflamm 2007;2007:69416.

29. Teixeira FB, Gomes BP, Ferraz CC, Souza-Fiho FJ, Zaia AA. Radiographic analysis of the development of periapical lesions in normal rats, sialoadenectomized rats and sialoadenectomizedimmunosuppressed rats. Endod Dent Traumatol 2000 Aug;16(4):154-157.
30. Yamasaki M, Kumazawa M, Khosaka T, Hiroshi N, Kameyama Y. Pulpal and periapical tissue reactions after experimental pulpal exposures in rats. J Endod 1994 Jan;20(1):13-17.

31. Yu SM, Stashenko P. Identification of inflammatory cells in developing rat periapical lesions. J Endod 1987 Nov;13(11):535540 .

32. Gerdes J, Lelle RJ, Pickartz H, Heidenreich W, Schwarting R, Kurtsiefer L, Stauch G, Stein H. Growth fraction in breast cancers determined in situ with monoclonal antibody Ki-67. J Clin Pathol 1986 Sep;39(9):977-980.

33. Gracia RL, Coltrera MC, Gown AM. Analysis of proliferative grade using anti-PCNA/cyclin monoclonal antibodies in fixed embedded tissue. Am J Pathol 1989 Apr;134(4):733-739.

34. Onuma H, Mastui C, Morohashi M. Quantitative analysis of the proliferation of epidermal cells using a human skin organ culture system and the effect of DbcAMP using markers of proliferation (BrdU, Ki-67, PCNA). Arch Dermatol Res 2001 Mar;293(3):133-138.

35. Chen SC, Marino V, Gronthos S, Bartold PM. Location of putative stem cells in human periodontal ligament. J Periodont Res 2006 Dec;41(6):547-553.

36. Lin N-H, Menicanin D, Mrozik K, Gronthos S, Bartold PM. Putative stem cells in regenerating human periodontium. J Periodont Res 2008 Oct;43(5):514-523.

37. Ohta S, Yamada S, Matsuzaka K, Inoue T. The behavior of stem cells and progenitor cells in the periodontal ligament during wound healing as observed using immunohistochemical methods. J Periodont Res 2008 Dec;43(6):595-603.

\section{ABOUT THE AUTHORS}

\section{Sultan Zeb Khan (Corresponding Author)}

Post Doctorate Fellow, Department of Oral Health Science Center Tokyo Dental College, Chiba, Japan, Phone: 0081432703582, e-mail: sultanzb@yahoo.com

\section{Eitoyo Kokubu}

Lecturer, Department of Microbiology, Tokyo Dental College, Chiba Japan

\section{Morito Tsuruoka}

Visiting Lecturer, Department of Clinical Pathophysiology, Tokyo Dental College, Chiba, Japan

\section{Satoshi Murakami}

Assistant Professor, Department of Clinical Pathophysiology, Tokyo Dental College, Chiba, Japan

\section{Kenichi Matsuzaka}

Associate Professor, Department of Clinical Pathophysiology, Tokyo Dental College, Chiba, Japan

\section{Takashi Inoue}

Professor, Department of Clinical Pathophysiology, Tokyo Dental College, Chiba, Japan 